\title{
Documentación de la medicina tradicional creole de Laguna de Perlas
}

\author{
Vilma Marie Anderson Dixon
}

\section{INTRODUCCIÓN}

En su mayoría, la población de la comunidad de Laguna de Perlas es creole, uno de los grupos étnicos nicaragüense más estrechamente relacionados con el fenotipo y la identidad sociocultural africana. En esta comunidad, la medicina tradicional es una especialidad de perfil amplio en la cosmovisión de estos comunitarios (recursos naturales, ser humano, Dios), que emplean técnicas y procedimientos ancestrales para promoción, prevención de enfermedades, tratamiento y rehabilitación de la Salud. La medicina natural y tradicional está integrándose armónicamente con la medicina convencional del sistema de salud nicaragüense en Pearl Lagoon.

\section{Medicinas tradicionales de uso popular en Pearl Lagoon}

Tumtum (flor del lirio), sorosi (bejuco), vervine (verbena), barsely (árbol de eucalipto), guacu (bejuco), caisney patta (bejuco), hoja de mango mechudo (hairy mango leaves), café en grano. De los diez médicos tradicionales entrevistados, solamente uno mencionó una planta medicinal diferente: el tumtum o flor de lirio.

\section{Enfermedades tratadas con medicina tradicional}

Cálculos renales, shingle (problema de la piel), albumina (problema renal), heridas, grasa en el hígado, hemorroides, problemas de próstata (stopage of water), asma, artritis, dolor de vientre, aire en los músculos, dolor de oídos, cataratas en los ojos (felam in the eyes), lepra de montaña, picadura de pescado (stingre), diabetes, impotencia, quistes, gastritis estomacal, born with call, parásitos, convulsiones causadas por los nervios, quebradura, infección vaginal.

\section{Enfermedades, medicinas tradicionales y recetas}

\begin{tabular}{|l|l|l|}
\hline \multicolumn{1}{|c|}{ Enfermedades } & \multicolumn{1}{|c|}{ Medicina tradicional } & Receta \\
\hline Cálculos renales. & $\begin{array}{l}\text { Ciasy pata, pisabed root, } \\
\text { wandering due, soar sap leaf. }\end{array}$ & $\begin{array}{l}\text { En un litro de agua hervir juntos un puñado de cada uno } \\
\text { de los ingredientes de la receta. Luego se toma en ayunas } \\
\text { por quince días. }\end{array}$ \\
\hline $\begin{array}{l}\text { Shingle (problema de la } \\
\text { piel). }\end{array}$ & $\begin{array}{l}\text { Sorrosi, guacu, hoja de mango, } \\
\text { serocontil, wild sage, hoja de } \\
\text { guanábana, ajo. }\end{array}$ & $\begin{array}{l}\text { Hervir sorrosi, guacu, hoja de mango, wild sage y hoja } \\
\text { de guanábana. Se deja enfriar y se lava el área afectada } \\
\text { de la piel. También, el ajo cortado en pedacitosse toma } \\
\text { con agua diariamente. }\end{array}$ \\
\hline Heridas. & $\begin{array}{l}\text { Machacar dos docenas de hoja de guanábana en cuatro } \\
\text { tazas de agua, hasta que el color del agua se vuelve verde } \\
\text { olivo, y se lava la herida suavemente. }\end{array}$ \\
\hline
\end{tabular}




\begin{tabular}{|c|c|c|}
\hline Grasa en el hígado. & $\begin{array}{l}\text { Serocontil o la hoja amarilla } \\
\text { del árbol de papaya. }\end{array}$ & $\begin{array}{l}\text { Hervir diariamente tres hojas en una taza de agua, se } \\
\text { toma en ayuno por una semana y se repite el tratamiento } \\
\text { durante dos semanas (una semana de por medio). Si no } \\
\text { se tiene al alcance el serocontil se puede substituir con } \\
\text { hoja de papaya. }\end{array}$ \\
\hline Problemas de próstata. & $\begin{array}{l}\text { Hojas de guanábana, casney } \\
\text { pata y albahaca. }\end{array}$ & $\begin{array}{l}\text { Se pone a hervir, en cuatro litros (un galón ) de agua, cuatro } \\
\text { hojas de cada uno de los tres ingrediente, se apaga el fuego } \\
\text { y se deja reposar. Luego se toma como té. }\end{array}$ \\
\hline Asma. & $\begin{array}{l}\text { Eucalipto, man to man, botton } \\
\text { leaf, ram goat dash a lamb y } \\
\text { limon. }\end{array}$ & $\begin{array}{l}\text { Hervir por media hora un puño de cada una de las hojas } \\
\text { antes mencionadas, con cuatro tazas de agua; se retiran } \\
\text { las hojas y mientras sigue hirviendo el agua se agrega } \\
\text { una taza de azúcar y se deja hervir hasta llegar a punto } \\
\text { de jalea, se agrega limón al gusto y se toma tres veces } \\
\text { diario por dos días. }\end{array}$ \\
\hline Artritis. & $\begin{array}{l}\text { Hoja de mango, eucalipto, } \\
\text { y provision bark. }\end{array}$ & $\begin{array}{l}\text { Se pone a hervir, por } 15 \text { minutos, } 1 / 2 \text { galón de agua con } \\
\text { una docena de hojas de mango, dos docenas de hojas de } \\
\text { eucalipto y } 1 / 4 \text { de libra de provisión bark. Cuando esté } \\
\text { tibio se humedece por la noche el lugar adolorido y se } \\
\text { seca al aire libre. Esto se hace antes de acostarse, hasta } \\
\text { que se logra un resultado positivo. }\end{array}$ \\
\hline Dolor de vientre. & Hoja de guanábana. & $\begin{array}{l}\text { Hervir siete hojas de guanábana en un litro de agua por tres } \\
\text { minutos. Se destapa por diez minutos, luego se vierte en } \\
\text { una bacinilla y el afectado se sienta en ella durante diez } \\
\text { minutos, hasta que esté a una temperatura del ambiente, } \\
\text { esto se hace por la noche antes de acostarse. }\end{array}$ \\
\hline Aire en los músculos. & Ajo. & $\begin{array}{l}\text { Triturar tres dientes de ajo envueltos en un pedazo de } \\
\text { algodón y se frota en el área afectada. }\end{array}$ \\
\hline Dolor de oído. & Ajo/caisney patta & $\begin{array}{l}\text { Envolver un diente de ajo en un pedazo de algodón, } \\
\text { poniendo atención en que esté bien cubierto para no irritar } \\
\text { la piel. Se machaca } 3 \text { ó } 4 \text { hojas de caisney patta (bejuco) } \\
\text { hasta obtener el jugo. Luego se le da un poco de calor (a } \\
\text { la temperatura de la sangre).y se aplica únicamente dos o } \\
\text { tres gotitas en el oído.. }\end{array}$ \\
\hline Cataratas en los ojos. & Pisabed leaves & $\begin{array}{l}\text { Lavar de seis a siete hojas -las más tiernas-, luego se } \\
\text { trituran en un pedazo de tela limpia y del jugo extraído } \\
\text { se aplican diariamente dos gotas en el ojo afectado, hasta } \\
\text { que desaparece la catarata. }\end{array}$ \\
\hline Lepra de la montaña. & Guacu, casney pata, sorrosi. & $\begin{array}{l}\text { Se deja secar en la sombra un puño de hojas de cada } \\
\text { ingrediente de la medicina. Luego se pone a tostar a fuego } \\
\text { lento en un sartén. Ya tostado se saca del fuego y se tritura } \\
\text { hasta convertirlo en polvo. } \\
\text { Aparte hervir un puño de cada hoja en } 1 / 2 \text { litro de agua } \\
\text { y dejarla enfriar. Ya fría con esta agua se lava la herida } \\
\text { suavemente, asegurando que quede limpia; sobre la } \\
\text { humedad del lavado espolvorear las hojas trituradas sobre } \\
\text { la herida. Repetir esta cura todos los días hasta que se cure. }\end{array}$ \\
\hline
\end{tabular}




\begin{tabular}{|l|l|l|}
\hline Diábetes. & $\begin{array}{l}\text { Vervine, barsley, caisney pata, } \\
\text { flor de Jamaica, achiote, } \\
\text { canela. }\end{array}$ & $\begin{array}{l}\text { Hervir tres ramitas de vervine, tres de albahaca y tres de } \\
\text { caisney pata, en dos litros de agua, y tomar en vez de } \\
\text { agua por todo el día. } \\
\text { También se prepara té de flor de Jamaica, para tomar } \\
\text { diario una taza en ayunas, junto con tres semillas de } \\
\text { achiote, diario. }\end{array}$ \\
\hline $\begin{array}{l}\text { Quistes en el útero o el } \\
\text { ovario. }\end{array}$ & $\begin{array}{l}\text { Ajo o wondering dew. botton } \\
\text { leaaves, pisabed root, sorosi, } \\
\text { caisny patta. }\end{array}$ & $\begin{array}{l}\text { Si padece de presión alta, no use el ajo, solo wondering } \\
\text { dew, botton leaves, pisabed, leaves pisabed root sorosi, } \\
\text { caisni patta. En un galón de agua hirviendo agregue } \\
\text { un puño de cada ingrediente: wondering dew, botton } \\
\text { leaves, sorrosi, caisni patta y la ráz entera de una planta } \\
\text { de pisabed. Consumir cinco galones en una semana. } \\
\text { Descansar la semana siguiente y continuar en la otra. }\end{array}$ \\
\hline Gastritis estomacal. & Flor de Jamaica, papa rayada. & $\begin{array}{l}\text { Dejar cuatro flores de Jamaica en dos tazas de agua y } \\
\text { tomar el agua en ayunas. También se raya una papa o se } \\
\text { licúa, luego se echa en un vaso de agua, se cuela y se toma } \\
\text { el agua en ayunas.. }\end{array}$ \\
\hline Parásitos. & Ajo o cilantro & $\begin{array}{l}\text { Se confecciona una cadena de ajos y se coloca a la persona } \\
\text { que tiene parásitos. También, a una taza de agua hirviendo } \\
\text { se le agregan cuatro hojas de cilantro y se toma como té. }\end{array}$ \\
\hline Infección vaginal. & $\begin{array}{l}\text { Se calienta la sábila sobre el fuego, luego se parte en } \\
\text { dos mitades y se colocan en la parte baja del abdomen. } \\
\text { Después se prepara el alcanfor en pedazos pequeños, se } \\
\text { abre una gaza o algodón y se unta con alcanfor, luego se } \\
\text { amarra el algodón o la gaza con un hilo fuerte hasta hacer } \\
\text { un tampón al cual se le agrega aceite (una cucharada). } \\
\text { Después se coloca en la vagina y se deja allí. A los dos } \\
\text { días. Se extrae el hilo que se ha dejado largo y que asoma } \\
\text { fuera de la vagina. Se repite tres o cuatro veces más } \\
\text { después de siete días. }\end{array}$ \\
\hline Impón. aceite, hilo,
\end{tabular}

\section{Médicos tradicionales en Laguna de Perlas}

Fueron identificados nueve médicos tradicionales (seis hombres y tres mujeres) en Pearl Lagoon: Thedore N. Hebbert Taylor, Gretel Hebbert goff, Benjamín McCoy, César Stamp Hebbert, Lucila Allen Desouza, Wilfred McCoy Anderson, Elena Salomon Morales, Gadwin Lewis Anderson, James Desouza Taylor. 


\section{BIBLIOGRAFÍA}

Beer, Gaudy. \& Vanegas, Shanda, (2007) "Diagnostico para la Demarcación de las doce Comunidades Indígenas y Afro-descendientes de la Cuenca de Pearl Lagoon”. URACCAN recinto Bluefields. Instituto de Recursos Naturales, Medio Ambiente y Desarrollo Sostenible IREMADE.

Cunningham Mirna, \& Wilson White Ceferino (2010) Inventario y mapeo de Afro descendientes de la Costa Caribe de Nicaragua.

Gugliemi, Rene (2006) "Plan de Manejo de los Humedales de la Cuenca de Laguna de Perlas y Bluefields, 112 paginas.

Unesco. (2002). Glosario sobre el patrimonio cultural Inmaterial.

González, Ligia, M, Huete Mendoza Maximina, López Mairena Eugenio y Palacios Juana F. (2004) "Ïmpacto de Plantas Medicinales en la Salud Humana en la Colonia los Ángeles, Nueva Guinea. URACCAN, Nueva Guinea, Nicaragua.

Inventario y Mapeo de recursos culturales de los Pueblos Indígenas y afro-descendientes de la costa caribe de Nicaragua. "Programa revitalización cultural y desarrollo productivo creativo en la costa caribe de Nicaragua,Julio, 2009 y febrero,2011.

Osorno Durango, Edison Javier, Septiembre, 2009, “Aspectos Básicos de Farmacognosia” Facultad de Química Farmacéutica, Universidad de Antioquia.

Organización Mundial de la Salud, Diciembre, (2008) "Medicina Tradicional Centro de Prensa, Nota descriptiva, No.134.

Sampieri, Roberto y colaboradores (2006) "Metodología de la Investigación. Mc. Graw Hill, Interamericana. D.C 